\title{
$34^{\text {o }}$ Congreso Uruguayo de Cardiología
}

Estimados amigos:

En nombre del Comité Organizador nos complace informarles que la 34를 edición del Congreso Uruguayo de Cardiología se llevará a cabo entre los días 2 y 4 de diciembre del corriente año en el Centro de Convenciones del Radisson Montevideo Victoria Plaza Hotel.

Luego de un exitoso y fructífero evento en Punta del Este en noviembre de 2017, regresamos este año a nuestra capital. Sabemos que cada sede tiene sus atractivos y sus inconvenientes. Creemos que una alternancia balanceada entre Montevideo y lugares estratégicos del interior de nuestro país como sedes para el congreso será una política futura de nuestra Sociedad.

El Congreso Uruguayo de Cardiología nuclea cada año a cientos de participantes con el objetivo de compartir actualizaciones en temas relacionados con la cardiología y la cirugía cardíaca. La amplia disponibilidad de información a través de los medios digitales ha afectado sin dudas al mundo de los congresos, y no hemos sido la excepción. Ya no se trata de asistir al congreso para escuchar la información inédita, la novedad de último minuto, o para sacar apuntes en una conferencia sobre datos a los que nunca más podremos acceder. Todo eso está al alcance de nuestra computadora y hoy en día al alcance de nuestro celular. En un segundo. Sin embargo, de una forma que podríamos catalogar hasta de paradójica, ello nos ha aislado a la mayoría de nosotros en nuestro pequeño mundo personal de una manera preocupante. No es fácil contrarrestar este fenómeno.

Estamos convencidos de que la riqueza de una actividad como la que lleva a cabo el Congreso Uruguayo de Cardiología radica en que nos da la oportunidad de recibir y de compartir esa información con colegas locales y extranjeros, pero como comunidad cardiológica. Nos da la maravillosa oportunidad de compartir nuestra experiencia o impresiones sobre determinado tema o actividad con expertos destacados, con nuestros jefes, con compañeros de trabajo, con compañeros de estudio, o incluso hasta con nuestro poco conocido vecino de butaca. Nos permite planificar cambios en nuestra manera de trabajar, o establecer planes para mejorar nuestra práctica. Nos contacta con colegas de nuestro entorno laboral de una manera diferente. Nos contacta con nuestra competencia. Nos contacta con el mundo. Nos saca del aislamiento.

El congreso debe desarrollarse en un entorno lo más favorable posible para lograr sus objetivos. La temática debe ser atractiva, de actualidad, y las exposiciones didácticas y amenas. Apuntamos a la participación activa de nuestros socios, de los ámbitos más diversos de nuestro medio, en las diferentes mesas y simposios.

Es con esta idea que hemos venido trabajando con el Comité Organizador desde mediados del año 2017. Hemos elaborado un programa muy rico y variado en cuanto a su temática científica, que contempla el relacionamiento de nuestra Sociedad con organizaciones cardiológicas internacionales y promueve la participación de destacados colegas de nuestro medio.

Se llevarán a cabo simposios conjuntos de primordial importancia con la Sociedad Europea de Cardiología , con el Colegio Americano de Cardiología , con la Sociedad Española de Cardiología, con la Asociación Americana de Cirugía Torácica y con la Sociedad Argentina de Cardiología y otras sociedades de la región. La Sociedad Latinoamericana de Cardiología Intervencionista llevará a cabo sus XXXVI Jorna- 
das Regionales -duodécimas de la Región Cono Sur- integradas a la actividad principal del congreso y orientadas al cardiólogo clínico. La comisión de Educación Médica Continua organizará el tradicional y siempre atractivo Curso pre Congreso. Cada comité de la Sociedad Uruguaya de Cardiología en actividad realizará un simposio donde profundizará sobre aspectos específicos de su subespecialidad. Se están organizando actividades dirigidas a la comunidad en conjunto con autoridades sanitarias de nuestro país.

Contaremos con invitados de excepcional jerarquía, procedentes de Sudamérica, Estados Unidos, Canadá, España y Holanda, que expondrán sobre temas de actualidad y compartirán mesas con destacados cardiólogos y cirujanos cardíacos locales.

Solo resta invitarlos a participar activamente de nuestro 34ํㅡㄹ Congreso Uruguayo de Cardiología. El mayor evento cardiológico del año debe ser una oportunidad de integración para todos. Los mantendremos informados periódicamente sobre el desarrollo del encuentro.

Los saludamos afectuosamente.

Por Comité Organizador del 34 Congreso Uruguayo de Cardiología,

\author{
Dr. Pablo Díaz Artigas \\ Presidente
}

